\title{
DESEMPENHO, CARACTERÍSTICAS DA CARCAÇA E DA CARNE DE CORDEIROS CONFINADOS COM NÍVEIS CRESCENTES DE BAGAÇO DE LARANJA EM SUBSTITUIÇÃO AO MILHO
}

\section{PERFORMANCE, CARCASS AND MEAT CHARACTERISTICS OF LAMBS IN FEEDLOT FED DIETS WITH INCREASING LEVELS OF FRESH ORANGE PULP REPLACING CORN}

\author{
Fabiola Cristine de Almeida Rego ${ }^{1^{*}}$ ORCID - http://orcid.org/0000-0003-4516-7632 \\ Lisiane Dorneles de Lima² ORCID - http://orcid.org/0000-0001-8543-0672 \\ Josyane Baise ${ }^{1}$ ORCID - http://orcid.org/0000-0003-2607-7922 \\ Marta Juliane Gasparini ${ }^{1}$ ORCID - http://orcid.org/0000-0001-8896-942X \\ Josiane Ito Eleodoro ${ }^{1}$ ORCID - http://orcid.org/0000-0002-1804-0903 \\ Marcelo Diniz dos Santos ${ }^{3}$ ORCID - http://orcid.org/0000-0002-5486-8353 \\ Marilice Zundt ${ }^{4}$ ORCID - http://orcid.org/0000-0001-9551-9195 \\ ${ }^{1}$ Universidade do Norte do Paraná, Londrina, PR, Brasil. \\ ${ }^{2}$ EMBRAPA Caprinos e Ovinos, Sobral, CE, Brasil \\ ${ }^{3}$ Universidade de Cuiabá, Cuiabá, MT, Brasil \\ ${ }^{4}$ Universidade do Oeste Paulista, Presidente Prudente, SP, Brasil. \\ *Autora para correspondência - fabiolaregogrecco@gmail.com
}

\section{Resumo}

O objetivo desta pesquisa foi avaliar o desempenho e as características quantitativas e qualitativas da carcaça e da carne de cordeiros terminados com diferentes níveis de substituição do milho moído pelo bagaço de laranja. Foram utilizados 32 machos inteiros, da raça Texel, com peso médio inicial de 16 $\pm 2,5 \mathrm{~kg}$. Os animais foram distribuídos em delineamento inteiramente casualizado em quatro tratamentos experimentais, com oito repetições cada. Os tratamentos foram quatro níveis de substituição $(0,33,66$ e 100\%) do milho moído pelo bagaço de laranja na matéria seca. Os animais foram abatidos quando atingiram $32.5 \mathrm{~kg}$ de peso vivo. $O$ ganho de peso médio diário (188 g por dia), o ganho de peso total $(16 \mathrm{~kg})$ e o peso ao abate $(32,5 \mathrm{~kg})$ foram semelhantes entre os tratamentos. A área de olho de lombo e a espessura de gordura subcutânea diminuíram linearmente em função dos níveis de inclusão do bagaço de laranja na dieta. As características de desempenho e de carcaça não foram alteradas pela substituição parcial ou total do milho por bagaço de laranja. Entretanto, a substituição total do milho por bagaço de laranja reduziu em 32\% a AOL e em 35\% a espessura de gordura subcutânea.

Palavras-chave: área de olho de lombo, cor da carne, ganho de peso, rendimento de carcaça.

\footnotetext{
Abstract

The objective of this research was to evaluate the performance, the quantitative and qualitative carcass and meat characteristics of finished lambs with different levels of fresh orange pulp replacing corn. Thirty-two whole males of Texel breed were used, with a mean initial weight of $16 \pm 2.5 \mathrm{~kg}$. The
} 
animals were distributed in a completely randomized design in four experimental treatments, with eight replicates each. The treatments were four levels of orange pulp $(0,33,66$ and 100\%) replacing corn on dry matter. The animals were slaughtered when they reached $32.5 \mathrm{~kg}$ of live weight. Average daily weight gain (188 g per day), total weight gain (16 kg) and slaughter weight $(32.5 \mathrm{~kg})$ were similar among treatments. The loin eye area and subcutaneous fat thickness decreased linearly as a function of the orange pulp inclusion levels in the diet. The performance and carcass characteristics were not altered by the partial or total replacement of the corn with orange pulp. However, the total replacement of corn with orange pulp reduced loin eye area by $32 \%$ and subcutaneous fat thickness by $35 \%$.

Key-words: loin eye area, meat color, weight gain, carcass yield.

Recebido em: 28 de novembro de 2017.

Aceito em: 19 de novembro de 2018.

\section{Introdução}

A crescente demanda por carne ovina registrada nos últimos anos impulsionou o aumento da produção de cordeiros para o abate, gerando a necessidade de melhoria nas técnicas de exploração. Sendo assim, a adoção de algumas estratégias de produção intensiva faz-se necessária na ovinocultura, principalmente em regiões em que o custo da terra é considerado elevado. Nesse sentido, pesquisas têm mostrado como alternativa eficiente para a terminação de cordeiros o uso do confinamento, ferramenta que permite encurtar o ciclo de produção e disponibilizar no mercado carcaças de animais jovens e de melhor qualidade ${ }^{(1-2)}$. No entanto, deve-se observar o custo da alimentação, pois o concentrado da dieta é a fração mais onerosa no sistema de produção(3), correspondendo de $60 \%$ a $70 \%$ desses custos.

Desse modo, os alimentos alternativos, como os resíduos originados na produção agrícola e na agroindústria em dietas de ruminantes, podem desempenhar papel primordial na economicidade de um sistema de produção. Diversos resíduos gerados por culturas agrícolas, na maioria das vezes, podem ser aproveitados na alimentação animal, reduzindo assim a contaminação ambiental e desempenhando um papel primordial na economicidade de um sistema de produção.

Entre os coprodutos, inclui-se o bagaço de laranja, um ingrediente de alta densidade energética, com efeitos positivos na fermentação ruminal em comparação a alimentos ricos em amido; uma vez que o bagaço de laranja contém moderados teores de FDN e elevados teores de pectina, ele estimula a produção de ácido acético em detrimento do ácido lático ${ }^{(4)}$.

Diferentemente dos grãos de cereais, como milho e sorgo, o bagaço de laranja não contém teores significativos de amido, mas é rico em carboidratos não fibrosos $(53,2 \%)$, teores de fibra em detergente neutro e ácido de $32 \%$ e $28 \%$, respectivamente, $1,8 \%$ de extrato etéreo e $7,8 \%$ de proteína bruta ${ }^{(5)}$.

Portando, o presente estudo teve como objetivo avaliar o uso do bagaço de laranja em substituição ao milho moído na terminação de cordeiros Texel e seus efeitos no desempenho animal, nas características da carcaça e da carne. Objetivou ainda avaliar a viabilidade econômica da alimentação com o uso do bagaço de laranja em diferentes níveis. 


\section{Material e Métodos}

O experimento foi conduzido no município de Florestópolis, região norte do Paraná, Brasil, entre os meses de setembro e dezembro. Esta pesquisa foi aprovada pelo comitê de ética para o uso de animais da UNOPAR (CEA) e está de acordo com os princípios éticos de experimentação animal, seguindo o protocolo $011 / 12$.

Foram utilizados 32 machos inteiros, mestiços da raça Texel (7/8), com peso médio inicial de $16 \pm$ $2,5 \mathrm{~kg}$. Os animais foram distribuídos em delineamento inteiramente casualizado em quatro tratamentos experimentais, com oito repetições. Os tratamentos foram quatro níveis de substituição $(0 \%, 33 \%, 66 \%$ e $100 \%)$ do farelo de milho pelo bagaço de laranja, na matéria seca da dieta. O bagaço de laranja foi adquirido da Cooperativa de Cafeicultores de Maringá Ltda (COCAMAR), produtora de suco de laranja situada na cidade de Rolândia - PR.

Os animais foram confinados em baias coletivas e cobertas, suspensas, com piso de madeira ripado. Previamente ao início do experimento, os cordeiros foram vermifugados. As dietas experimentais foram formuladas para atender às exigências nutricionais de cordeiros de porte médio e ganho de peso estimado em $200 \mathrm{~g} /$ dia, de acordo com as recomendações do $\mathrm{NRC}^{(6)}$, contendo $30 \%$ de volumoso e 70\% de concentrado, misturados diretamente no cocho, e acesso irrestrito à água (Tabela 1).

Tabela 1. Proporção de ingredientes e composição química das dietas experimentais (\% MS) de cordeiros alimentados com dietas contendo milho moido em substituição ao bagaço de laranja

\begin{tabular}{lcccc}
\hline \multirow{2}{*}{ Ingredientes } & \multicolumn{4}{c}{ Níveis de substituiçã $\mathbf{1}^{\mathbf{1}}$} \\
\cline { 2 - 5 } & $\mathbf{0 \%}$ & $\mathbf{3 3 \%}$ & $\mathbf{6 6 \%}$ & $\mathbf{1 0 0} \%$ \\
\hline Feno de aveia & 30,4 & 30,28 & 30,28 & 30,28 \\
Bagaço de laranja & - & 16,89 & 33,79 & 50,56 \\
Milho moido & 50,56 & 33,79 & 16,89 & - \\
Farelo de soja & 17,54 & 17,54 & 17,54 & 17,54 \\
Sal mineral & 1,50 & 1,50 & 1,50 & 1,50 \\
\hline Composição quimica & & & & \\
\hline Matéria seca & 89.00 & 66.00 & 52.00 & 43.00 \\
Matéria mineral & 4,16 & 5,30 & 6,76 & 7,93 \\
Extrato etéreo & 2,91 & 2,37 & 2,15 & 2,29 \\
Fibra em detergente neutro & 29,2 & 32,1 & 37,6 & 42,3 \\
Fibra em detergente ácido & 12,2 & 16,5 & 19,8 & 24,2 \\
Carboidratos totais & 75,9 & 74,0 & 70,6 & 70,4 \\
Carboidratos não fibrosos & 46,7 & 41,9 & 33,0 & 28,0 \\
Proteina bruta & 17,0 & 18,3 & 20,5 & 19,4 \\
Proteina insolúvel detergente neutro & 1,48 & 0,90 & 1,48 & 2,21 \\
Proteina insolúvel detergente ácido & 1,08 & 0,97 & 1,56 & 1,85 \\
NDT ${ }^{2}$ & 73,68 & 70,44 & 67,76 & 51,72 \\
\hline
\end{tabular}

${ }^{1}-0 \%$ de bagaço de laranja; $33 \%$ de substituição do milho moído pelo bagaço de laranja; $66 \%$ de substituição do milho moído pelo bagaço de laranja $100 \%$ de substituição do milho moído pelo bagaço de laranja; ${ }^{2}$ - NDT - nutrientes digestiveis totais estimados pelo $\mathrm{NCR}^{(10)}$

A alimentação foi dividida em duas refeições, fornecidas às 8 e às 16 horas. Foram recolhidas e pesadas as sobras de alimentos (mantidas em torno de $15 \%$ do ofertado), antes do trato da manhã, para o ajuste da quantidade ofertada e o cálculo do consumo de matéria seca total por dia do lote 
(CMS). Avaliaram-se os teores de matéria seca (MS), proteína bruta (PB), matéria mineral (MM), extrato etéreo (EE), fibra em detergente neutro (FDN), fibra em detergente ácido (FDA, proteína insolúvel em detergente neutro (PIDN) e proteína insolúvel em detergente ácido (PIDA), segundo procedimentos descritos em Mizubuti et al. ${ }^{(7)}$ (2009)). Foram estimados os carboidratos totais (CT), os carboidratos não fibrosos $(\mathrm{CNF})^{(8)}$ e os nutrientes digestíveis totais (NDT), segundo equações do $\mathrm{NRC}^{(9)}$. As análises químico-bromatológicas foram realizadas no Laboratório de Bromatologia da Universidade Norte do Paraná.

O período total de confinamento foi de 89 dias, de modo que os primeiros 14 dias foram destinados à adaptação dos animais às instalações e à dieta alimentar. Os animais foram pesados no dia zero do experimento, a cada 21 dias e um dia antes do abate (após jejum de 16 horas) para acompanhamento do ganho de peso diário.

$\mathrm{O}$ abate foi realizado em abatedouro frigorífico, utilizando as normas de abate humanitário, quando os animais estavam em média com $32.5 \mathrm{~kg}$ de peso corporal. Foram pesados em jejum, para obtenção do peso corporal ao abate (PCA, $\mathrm{kg}$ ) e para as estimativas do ganho de peso total no período (GPT, $\mathrm{kg}$ ) e ganho de peso vivo diário (GPD, g). Para a obtenção do peso de carcaça quente (PCQ), os pés, a cabeça e os componentes internos foram removidos para a pesagem da carcaça. Em seguida, o trato gastrintestinal foi retirado e esvaziado para a obtenção do peso corporal vazio ( $\mathrm{PCV}=\mathrm{PCA}$ - conteúdo gastrintestinal). Em seguida, as carcaças permaneceram na câmara fria, a $4{ }^{\circ} \mathrm{C}$, por 24 horas, e foram pesadas para obter o peso de carcaça fria (PCF). O rendimento de carcaça quente (RCQ) foi determinado pela razão entre o PCQ e o PCA ( $R C Q=P C Q / P C A ~ x ~ 100)$, enquanto o rendimento de carcaça fria, pela razão entre o PCF e o PCA (RCF= PCF/PCA x 100). Para a determinação do rendimento biológico $(\mathrm{RB})$, utilizou-se a razão entre $\mathrm{PCQ}$ e $\mathrm{PCV}(\mathrm{RB}=\mathrm{PCQ} / \mathrm{PCV} \times 100)$. A perda por resfriamento (PPR) foi feita pela diferença percentual entre os pesos das carcaças antes e após o resfriamento $[\mathrm{PPR}=(\mathrm{PCQ}-\mathrm{PCF}) / \mathrm{PCQ} \times 100]$, expressa em porcentagem ${ }^{(10)}$.

Após a pesagem da carcaça fria, foram realizadas as avaliações de conformação, segundo a classificação europeia de carcaças (superior, excelente, muito boa, boa, normal e pobre), e acabamento em gordura (variando de 1 a 5 , do ausente ao abundante), conforme Sanudo et al. ${ }^{(11)}$.

Realizaram-se também as medidas objetivas da carcaça: comprimento externo da carcaça, largura do tórax, largura do dorso, largura de garupa, perímetro da perna e perímetro de braço, conforme descrito em Osorio \& Osorio ${ }^{(10)}$.

Após as avaliações descritas, as carcaças foram seccionadas na altura entre a $12^{\mathrm{a}}$ e a $13^{\mathrm{a}}$ costelas para a retirada do músculo Longíssimus dorsi. Em seguida, ainda no abatedouro, foram aferidas a área de olho de lombo e a espessura de gordura do músculo ${ }^{(12)}$, com o uso de um paquímetro digital. Em seguida, esse músculo foi enviado ao Laboratório de Nutrição Animal, da Universidade Estadual de Londrina, para estimar a taxa de marmoreio, de forma subjetiva, utilizando-se padrões fotográficos propostos pela American Meat Science Association(13), em que são atribuídas subjetivamente, pela mesma pessoa, notas de 1 a 10 (1 - traços de marmoreio e 10 - marmoreio abundante).

O músculo foi fatiado em 5 porções (bifes): 3 bifes (de $3 \mathrm{~cm}$ cada) para força de cisalhamento; 1 bife $(2 \mathrm{~cm})$ para avaliar cor, $\mathrm{pH}$ e perda de água por pressão, 1 bife $(3 \mathrm{~cm})$ para análises centesimais e para estimar perdas por descongelamento e cocção das carnes.

As variáveis cor da carne, $\mathrm{pH}$ e perda de água por pressão foram realizadas no mesmo dia da coleta 
da carne (24 horas após o abate), sendo o restante das porções congeladas para posteriores análises.

A cor da carne foi mensurada 20 minutos após efetuar o corte da carne, usando o colorímetro portátil KONICA MINOLTA, com iluminante D65 e $10^{\circ}$ ângulo de inclinação (Tokyo, JP) para avaliação dos componentes $\mathrm{L}^{*}$ (luminosidade), $\mathrm{a}^{*}$ (componente vermelho-verde) e b* (componente amareloazul), que foram expressos pelo sistema de cor CIELAB, conforme metodologia descrita em Houben et al. ${ }^{(14)}$. Foram efetuadas medidas em três pontos de cada amostra de carne, após 20 minutos da realização do seu corte. $\mathrm{O}$ pH da carne foi feito com o uso de peagâmetro TESTO® 205 , com eletrodo de inserção e resolução de 0.01 unidades de $\mathrm{pH}$.

Da mesma porção de carne, foi seccionada uma amostra de 5 g para estimar a perda de água por pressão (PAP), utilizando o método de aplicação de pressão, sobrepondo um peso de 10 quilos à carne, durante 5 minutos, e efetuando o peso da carne antes e após o uso da pressão, conforme metodologia descrita em Fernandes Junior et al. ${ }^{(15)}$.

Para a determinação da perda por descongelamento (PDESC), as amostras foram pesadas, congeladas e, após o descongelamento (em temperatura de $5^{\circ} \mathrm{C}$, por 24 horas), por meio da razão entre o peso da amostra descongelada e o peso da amostra congelada multiplicada por 100 . Na sequência, foi realizada a cocção da carne em forno a gás, pré-aquecido à temperatura de $170{ }^{\circ} \mathrm{C}$, até atingirem 70 ${ }^{\circ} \mathrm{C}$ no seu centro geométrico, mensurada através de um termômetro digital. A perda pela cocção (PCOC) foi à razão entre a peso da amostra refrigerada sobre a amostra assada, expressas em porcentagem do peso inicial.

Para determinar a composição química da carne, as amostras foram descongeladas em geladeira por 24 horas e posteriormente moídas. Após esse período, as amostras foram colocadas em estufa de ar forçado a $55^{\circ} \mathrm{C}$, por 72 horas. Posteriormente, foram processadas em moinho tipo Willey (peneira de $1 \mathrm{~mm}$ ), para determinar a proteína bruta, umidade e cinzas.

Para o cálculo da viabilidade econômica do uso do bagaço de laranja, consideraram-se os custos das dietas utilizadas, o custo de aquisição do cordeiro magro e a receita da carcaça. O custo individual por $\mathrm{kg}$ de matéria seca de cada tratamento foi 0,$95 ; 0,83 ; 0,72$ e $0,60 \mathrm{R} \$$ para as dietas $0 \%, 33 \%, 66 \%$ e $100 \%$, respectivamente. O preço de aquisição do cordeiro magro foi de. O custo total por animal foi a soma do custo de alimentação por animal (em todo o período) e o valor de aquisição do cordeiro magro ( $\mathrm{R}$ \$ 6,00 por kg de peso vivo). A receita de carcaça foi o produto da média peso de carcaça e o preço de venda da carcaça por quilo $(\mathrm{R} \$ 18,00)$.

As análises estatísticas foram realizadas no pacote estatístico SAS (versão 9.2, SAS Institute Inc., Cary, NC). Inicialmente, foram realizadas análises de variância e as pressuposições de normalidade e de homogeneidade de variância foram verificadas. Após isso, para as características nas quais foi obtido p-valor menor que 0,05 no teste $\mathrm{F}$ da análise de variância, foram realizadas análises de regressão.

\section{Resultados}

A inclusão do bagaço de laranja não alterou as variáveis para desempenho e quantitativas da carcaça (Tabela 2). As características de conformação e acabamento de carcaça (Tabela 3), que são variáveis 
subjetivas, foram semelhantes entre as diferentes dietas $(\mathrm{p}>0,05)$. As características biométricas da carcaça apresentaram comportamento linear negativo $(p<0,05)$ em função da substituição do milho pelo bagaço de laranja, diminuindo os valores com o aumento da proporção de bagaço na dieta.

Os parâmetros avaliados na carne (Tabela 4) não apresentaram diferenças significativas ( $>0,05)$, exceto a área de olho de lombo e a espessura de gordura subcutânea, que reduziram seus valores com os incrementos nos níveis de substituição do milho pelo bagaço de laranja $(\mathrm{p}<0,05)$.

Tabela 2. Consumo de matéria seca do lote (CMS, $\mathrm{kg}$ e \% do PV), ganho de peso total por animal $(\mathrm{kg})$, ganho de peso médio diário por animal $(\mathrm{g} / \mathrm{dia})$, peso corporal ao abate $(\mathrm{PCA}, \mathrm{kg})$, peso de carcaça quente (PCQ, $\mathrm{kg}$ ), peso de carcaça fria (PCF, $\mathrm{kg}$ ), rendimento de carcaça quente (RCQ, \%), rendimento de carcaça fria ( $\mathrm{RCF}, \%$ ), rendimento biológico (RB, \%), perda por resfriamento (PPR, $\%$ ), em função do nível de substituição do milho moído pelo bagaço de laranja na dieta de cordeiros

\begin{tabular}{|c|c|c|c|c|c|c|c|}
\hline \multirow[t]{2}{*}{ Parâmetros } & \multicolumn{4}{|c|}{ Nivel de substituição } & \multirow[t]{2}{*}{${ }^{1}$ Equação de ${ }^{1}$} & \multirow[t]{2}{*}{${ }^{2} \mathbf{P}$} & \multirow[t]{2}{*}{${ }^{3} \mathrm{CV}(\%)$} \\
\hline & $0 \%$ & $33 \%$ & $66 \%$ & $100 \%$ & & & \\
\hline CMS (kg/lote/dia) & 7,80 & 8,18 & 8,98 & 8,88 & $\hat{\mathrm{Y}}=8,46$ & 0,62 & 17,25 \\
\hline CMS (\%) & 3,68 & 4,12 & 4,34 & 4,13 & $\hat{\mathrm{Y}}=4,07$ & 0,55 & 15,98 \\
\hline GPT (kg) & 15,5 & 17,5 & 16,8 & 15,2 & $\hat{\mathrm{Y}}=16,25$ & 0,51 & 21,27 \\
\hline GMD (g) & 180 & 200 & 190 & 180 & $\hat{\mathrm{Y}}=188,00$ & 0,72 & 24,60 \\
\hline PCA (kg) & 32,2 & 33,8 & 32,9 & 31,2 & $Y=32,5$ & 0,68 & 13,50 \\
\hline PCQ (kg) & 13,3 & 15,8 & 14,5 & 15,2 & $\mathrm{Y}=14,7$ & 0,18 & 15,00 \\
\hline PCF (kg) & 12,9 & 15,3 & 14,2 & 14,7 & $\mathrm{Y}=14,3$ & 0,18 & 15,00 \\
\hline RCQ (\%) & 45,9 & 47,09 & 47,09 & 45,9 & $Y=46,1$ & 0,43 & 18,80 \\
\hline $\mathrm{RCF}(\%)$ & 44,6 & 45,7 & 44,5 & 44,0 & $\mathrm{Y}=44,7$ & 0,43 & 18,90 \\
\hline RB (\%) & 51,1 & 51,8 & 51,5 & 50,9 & $\mathrm{Y}=51,3$ & 0,52 & 20,20 \\
\hline PPR (\%) & 2,8 & 2,8 & 2,9 & 2,9 & $\mathrm{Y}=2,9$ & 0,98 & 0,34 \\
\hline
\end{tabular}

" $0 \%$ do bagaço de laranja: $33 \%$ de substituição do milho moido pelo bagaço de laranja: $33 \%$ de substituição do milho moído pelo bagaço de laranja; $66 \%$ de substituição do milho moido pelo bagaço de laranja $100 \%$ de substituiçăo do milho moido pelo bagaço de laranja; 'Equaçăo de Regressăo = média dos tratamentos; ${ }^{2} \mathrm{P}$ - Probabilidade; ${ }^{3} \mathrm{CV}$ - Coeficiente de variaçào

Tabela 3. Caracteristicas subjetivas e biométricas da carcaça de cordeiros recebendo dietas com diferentes níveis de substituição do milho moido pelo bagaço de laranja na dieta de cordeiros

\begin{tabular}{|c|c|c|c|c|c|c|c|c|}
\hline \multirow[t]{2}{*}{${ }^{1}$ Parâmetros } & \multicolumn{4}{|c|}{ Nivel de substituição } & \multirow[t]{2}{*}{${ }^{2}$ Equação de Regressão } & \multirow[t]{2}{*}{${ }^{3} R^{2}$} & \multirow[t]{2}{*}{${ }^{4} \mathbf{P}$} & \multirow[t]{2}{*}{${ }^{5} \mathrm{CV}($} \\
\hline & $0 \%$ & $33 \%$ & $66 \%$ & $100 \%$ & & & & \\
\hline Conformação & 2,71 & 3,12 & 2,25 & 2,87 & $\hat{\mathrm{Y}}=2,74$ & - & 0,21 & 30,3 \\
\hline Acabamento & 2,0 & 2,50 & 2,01 & 1,87 & $\hat{\mathrm{Y}}=2,10$ & - & 0,36 & 35,4 \\
\hline $\mathrm{CE}(\mathrm{cm})$ & 55,1 & 54,7 & 52,6 & 52,5 & $\hat{\mathrm{Y}}=55,27-0,03 \mathrm{X}$ & 0,24 & 0,02 & 3,79 \\
\hline $\mathrm{PP}(\mathrm{cm})$ & 31,4 & 31,0 & 29,6 & 29,8 & $\hat{\mathrm{Y}}=30,5$ & - & 0,45 & 8,19 \\
\hline $\mathrm{PB}(\mathrm{cm})$ & 19,1 & 17,5 & 16,7 & 18,6 & $\hat{\mathrm{Y}}=19,23-0,08 \mathrm{X}$ & 0,57 & 0,01 & 8,03 \\
\hline $\mathrm{LD}(\mathrm{cm})$ & 18,6 & 17,9 & 14,9 & 14,6 & $\hat{\mathrm{Y}}=18, \overline{\mathrm{i}} \mathrm{1}-0,04 \mathrm{X}$ & 0,64 & 0,000 & 6,96 \\
\hline $\mathrm{LT}(\mathrm{cm})$ & 27,0 & 25,4 & 23,7 & 22,9 & $\hat{\mathrm{Y}}=26,82-0,04 \mathrm{X}$ & 0,64 & 0,000 & 4,94 \\
\hline $\mathrm{LG}(\mathrm{cm})$ & 32,7 & 29,8 & 29,3 & 25,5 & $\hat{\mathrm{Y}}=30,68-0,11 \mathrm{X}$ & 0,55 & 0,000 & 14,6 \\
\hline
\end{tabular}


Tabela 4. Caracteristicas fisicas e qualitativas do músculo Longissumus dorsi de cordeiros recebendo dietas com diferentes niveis de substituição do milho moido pelo bagaço de laranja

\begin{tabular}{|c|c|c|c|c|c|c|c|c|}
\hline \multirow[t]{2}{*}{ Parâmetros* } & \multicolumn{4}{|c|}{ Nível de substituição** } & \multirow{2}{*}{$\begin{array}{c}{ }^{1} \text { Equação de } \\
\text { Regressão }\end{array}$} & \multirow[t]{2}{*}{${ }^{2} \mathbf{P}$} & \multirow{2}{*}{ - } & \multirow[t]{2}{*}{${ }^{4} R$} \\
\hline & $0 \%$ & $33 \%$ & $66 \%$ & $100 \%$ & & & & \\
\hline $\mathrm{pH}$ (24 horas) & 5,5 & 5,5 & 5,5 & 5,6 & $\hat{\mathrm{Y}}=5,6$ & 0,77 & 2,1 & - \\
\hline Marmoreio (1 a 5) & 1,5 & 1,8 & 1,1 & 1,8 & $\hat{\mathrm{Y}}=1,6$ & 0,07 & 38,36 & - \\
\hline Coloração $\mathrm{L}^{*}$ & 42,9 & 41,8 & 41,5 & 40,2 & $\hat{\mathrm{Y}}=41,6$ & 0,26 & 7,4 & - \\
\hline Coloração a* & 14,0 & 12,7 & 13,4 & 12,3 & $\hat{\mathrm{Y}}=13,1$ & 0,78 & 15,4 & - \\
\hline Coloração b* & 10,3 & 9,39 & 9,86 & 9,23 & $\hat{\mathrm{Y}}=9,6$ & 0,33 & 11,1 & - \\
\hline PAP (\%) & 21,3 & 22,9 & 28,9 & 28,0 & $\hat{\mathrm{Y}}=25,2$ & 0,45 & 17.9 & - \\
\hline $\mathrm{AOL}\left(\mathrm{cm}^{2}\right)$ & 15,4 & 12,1 & 11,1 & 10,4 & $\hat{\mathrm{Y}}=14,5-$ & 0,0001 & 14,7 & 0,45 \\
\hline $\mathrm{EGS}(\mathrm{mm})$ & 0,70 & 0,82 & 0,73 & 0,45 & $\hat{\mathrm{Y}}=0,81-$ & 0,0068 & 29,2 & 0,34 \\
\hline Proteina (\%) & 21,19 & 21,88 & 22,74 & 22,20 & 22,06 & 0,90 & 17,49 & - \\
\hline Umidade (\%) & 71,59 & 70,82 & 71,86 & 70,26 & 71,32 & 0,78 & 12,40 & - \\
\hline Cinzas (\%) & 3,33 & 3,51 & 3,74 & 3,79 & 3,79 & 0,19 & 22,47 & - \\
\hline Lipideos totais (\%) & 2,80 & 2,37 & 1,93 & 2,38 & 2,30 & 0,44 & 47,55 & - \\
\hline PDESC (\%) & 6,35 & 6,27 & 6,25 & 7,27 & 6,58 & 0,68 & 33,96 & - \\
\hline $\operatorname{PCOC}(\%)$ & 28,71 & 30,52 & 28,19 & 29,72 & 29,21 & 0,64 & 12,81 & - \\
\hline
\end{tabular}

*Coloraçăo L - Luminosidade; Coloraçăo a - Intensidade de cor vermelha, Coloração b - Intensidade amarela; PAP . Perda de ảgua por pressăo, AOL.

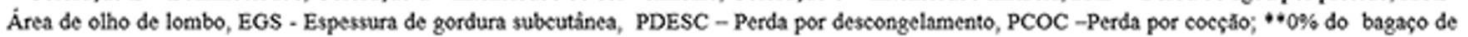
laranja; $33 \%$ de substituiçăo do milho moído pelo bagaço de laranja; $33 \%$ de substituição do milho moído pelo bagaço de laranja; $66 \%$ de substituiçẳo do milho moido pelo bagaço de laranja; $100 \%$ de substituiçăo do milho moido pelo bagaço de laranja; 'Equaçăo de Regressão"média dos tratamentos; : ip Probabilidade $-3 \mathrm{CV}$ - Coeficiente de variaçăo, ${ }^{\mathrm{R}} \mathrm{R}=$ Coeficiente de determinaçăo

Tabela 5. Viabilidade econômica relacionada à alimentação dos cordeiros recebendo dietas com diferentes niveis de substituição do milho moído pelo bagaço de laranja

\begin{tabular}{|c|c|c|c|c|}
\hline \multirow[b]{2}{*}{ Variáveis } & \multicolumn{4}{|c|}{ Nivel de substituição* } \\
\hline & $0 \%$ & $33 \%$ & $66 \%$ & $100 \%$ \\
\hline 1-Custo/ $\mathrm{kg}$ de MS da dieta total (RS/kg) & 0,95 & 0,83 & 0,72 & 0,60 \\
\hline 2-Custo cordeiro magro (RS) & 98,22 & 97,5 & 96,36 & 95,22 \\
\hline 3-Custo alimentação/animal no confinamento (RS) & 79,29 & 88,53 & 80,3 & 50,19 \\
\hline 4-Custo total/animal (RS) & 177,51 & 186,03 & 176,66 & 145,41 \\
\hline 5-Receita venda carcaça (RS) & 255,6 & 279,0 & 266,40 & 244,8 \\
\hline 6-Margem bruta /animal (RS) & 78,09 & 92,94 & 89,74 & 99,39 \\
\hline
\end{tabular}

\section{Discussão}

O consumo de matéria seca (Tabela 2) do lote não se alterou com os níveis de bagaço de laranja nas dietas e apresentou valor médio de $8,46 \mathrm{~kg}$ de matéria seca por lote por dia ( $\mathrm{p}>0,05)$, o que representaria, em média, $1 \mathrm{~kg}$ de matéria seca por animal e, em média, 4,07\% do peso vivo. Esses dados indicam que não houve limitação de consumo, mesmo no maior nível de substituição (100\%), em que o bagaço representou 50\% (Tabela 1) da matéria seca da dieta. Seguindo a mesma tendência, os resultados em desempenho (peso corporal ao abate, ganho de peso médio diário e ganho de peso 
total) foram semelhantes entre os tratamentos, apresentando valores médios de $32,5 \mathrm{~kg}, 188 \mathrm{~g}$ e 16,25 $\mathrm{kg}$, respectivamente. A semelhança entre os resultados de desempenho obtidos entre as dietas contendo porções de bagaço de laranja pode estar relacionada à semelhança em velocidade de digestão e também à semelhança em aceitação pelos animais, não provocando, dessa forma, prejuízo algum ao desempenho animal.

Em pesquisa testando a substituição do milho pela silagem de bagaço de laranja, observaram-se reduções lineares no consumo de matéria seca e de nutrientes ${ }^{(16)}$. Esse ganho de peso supera os achados de pesquisas recentes, com diferentes sistemas de terminação de cordeiros Texel x Corriedale e com ganhos variando de 97 a $135 \mathrm{~g}^{(17)}$. Já em outra pesquisa também com cordeiros Texel e Corriedale, detectaram-se ganhos médios de $208 \mathrm{~g}$ por dia, para os machos Texel ${ }^{(18)}$.

O rendimento de carcaça quente e fria foi também similar entre os diferentes níveis de substituição do milho por bagaço de laranja (Tabela 2). Da mesma forma, em pesquisa substituindo o milho moído por polpa cítrica, verificou-se que os pesos e os rendimentos de carcaça não foram afetados ${ }^{(19)}$. A perda por resfriamento não se alterou $(\mathrm{P}>0,05)$ com a inclusão do bagaço de laranja na dieta, apresentando média de 2,9\%. Já em pesquisa substituindo a silagem de milho por polpa cítrica úmida prensada, recomendou-se a substituição em até $75 \%$, sem afetar as características de carcaças ${ }^{(20)}$. O peso de carcaças quente e fria atingiu valores adequados, com médias de 14,7 e 14,3 $\mathrm{kg}$, respectivamente, para essas características, conforme recomendaram Galvani et al. ${ }^{(21)}$.

Segundo Astiz ${ }^{(22)}$, os rendimentos de carcaça ovina variam de $40 \%$ a $60 \%$, conforme a raça, os cruzamentos e o sistema de criação. Os dados desta pesquisa para rendimento biológico se encontram dentro dessa variação (média de 51,3\%). No entanto, Oliveira et al. ${ }^{(23)}$, trabalhando com animais Santa Inês, com peso de abate semelhante, verificaram RB médio de $56,29 \%$ para ovinos alimentados com resíduo de milho. Uma hipótese para os valores mais baixos poderia estar relacionada ao grau de acabamento, o qual pode ser considerado apenas satisfatório.

As medidas subjetivas de conformação e acabamento (Tabela 3) não diferiram significativamente $(\mathrm{P}>0,05)$ entre os tratamentos e apresentaram valores médios de 2,74 e 2,10 , respectivamente. Ao substituir o milho moído por glicerina bruta em níveis crescentes na dieta de cordeiros Texel, observou-se também escore de acabamento em gordura de $2,3^{(2)}$. Os valores observados para conformação (média de 2,74) indicam que os animais estavam no padrão próximo a 3 (carcaças retilíneas com boa cobertura muscular) e, para a avaliação de acabamento, os animais se encontravam no padrão 2 (carcaça com gordura escassa). Esses escores foram similares às observações feitas em cordeiros Santa Inês (puros ou mestiços), com médias de 2,71 e 2,66 para conformação e acabamento, respectivamente ${ }^{(24)}$.

No presente trabalho, houve efeito significativo para as medidas morfológicas da carcaça (Tabela 3), exceto perímetro da perna. Esses resultados divergem da maioria das pesquisas, que normalmente não observam diferenças em tais características. Em estudo semelhante, ao estudarem o efeito da substituição da silagem de milho pela polpa cítrica úmida prensada sobre as características de carcaça de cordeiros terminados em confinamento, observou-se efeito significativo apenas para comprimento de braço, que apresentou comportamento quadrático em função dos níveis de substituição ${ }^{(25)}$.

Os valores de $\mathrm{pH}$ (24 horas após o abate) da carne não alteraram significativamente $(\mathrm{P}>0,05)$ (Tabela 4) e apresentaram valores considerados dentro da faixa de $\mathrm{pH}$ normal para a carne ovina e semelhantes a trabalho que avaliou diferentes resíduos de frutas (maracujá, abacaxi, manga e banana) em 
substituição à silagem de sorgo, verificando valores entre 5,5 e 5,6 na região do lombo ${ }^{(26)}$. O fato de a dieta não ter influenciado no $\mathrm{pH}$ da carne é um fator positivo, uma vez que o $\mathrm{pH}$ da carne modifica suas características de qualidade (cor, capacidade de retenção de água e maciez), além de alterar as características organolépticas da carne. Do mesmo modo, não houve influência do nível de inclusão do bagaço de laranja na coloração da carne $(\mathrm{P}>0,05)$.

A luminosidade ( $\left.\mathrm{L}^{*}\right)$, a tonalidade de vermelho $\left(\mathrm{a}^{*}\right)$, a tonalidade de amarelo $\left(\mathrm{b}^{*}\right)$ e a perda de água por pressão da carne não foram significativamente influenciadas pelas dietas pesquisadas (Tabela 4).

Os resultados de área de olho de lombo e de espessura de gordura subcutânea diminuíram linearmente $(\mathrm{P}<0,05)$ com os níveis de inclusão do bagaço de laranja na dieta, admitindo-se assim que as carcaças não mantiveram padrão semelhante (Tabela 4). Em semelhante trabalho, avaliando-se os mesmos níveis de inclusão de polpa cítrica na dieta de terminação de cordeiros, não foi observada diferença significativa entre os tratamentos para AOL; entretanto, a relação concentrado: volumoso desse trabalho foi de 90:10(19), enquanto no presente trabalho foi 70:30, o que leva às diferenças nos resultados e nas proporções finais de bagaço na dieta. Em ovinos terminados em confinamento com volumosos à base de frutas e abatidos com $32 \mathrm{~kg}$, observaram-se valores de 14,9 a $16,9 \mathrm{~cm}^{2}(26)$.

Não houve efeito significativo $(\mathrm{P}>0,05)$ sobre os teores de proteína, umidade, cinzas e lipídeos totais (Tabela 4). Em pesquisa avaliando os efeitos da substituição do milho por polpa cítrica $(0 \%, 33 \%$, $67 \%$ e $100 \%$ ), não se detectaram alterações sobre os teores de umidade, proteína e cinzas ${ }^{(27)}$, estando semelhantes ao presente trabalho.

Os valores de perda de água por descongelamento e de perda de água por cocção na carne de cordeiros (Tabela 4) não se alteraram em função dos tratamentos ( $\mathrm{P}>0,05)$. A perda por cocção foi em média 29,21\% (Tabela 4), indicando elevada porcentagem de perdas ocorridas por ocasião da cocção, quando comparada a outros artigos, com perdas médias de $15,4 \%$ em carne de cordeiros da raça Morada Nova, com diferentes tipos de regime de terminação( ${ }^{(28)}$.

Em semelhante pesquisa utilizando a polpa cítrica em substituição ao milho na ração, com cordeiros da raça Santa Inês confinados, observaram-se índices de perda de água por cocção de 19,6; 22,5; 19,2; 19,7, para os tratamentos $0 \%, 33 \%, 67 \%$ e $100 \%$ de inclusão de polpa cítrica em substituição ao milho ${ }^{(19)}$.

A viabilidade econômica do uso de bagaço de laranja em substituição ao milho mostrou resultados positivos (Tabela 5), apresentando margem bruta de lucro por animal de R\$ 78,09 e R \$ 99,39 para as dietas com $0 \%$ e $100 \%$ de bagaço de laranja, respectivamente; ou seja, uma margem de lucros $26 \%$ maior. $\mathrm{O}$ fator que mais contribuiu para esse resultado foi que o custo por $\mathrm{kg}$ de matéria seca da dieta com $100 \%$ de bagaço de laranja foi $\mathrm{R} \$ 0,35$ inferior à dieta sem bagaço de laranja. O custo por kg de MS da ração total foi decrescente, à medida que se elevou a substituição do milho pelo bagaço de laranja. Isto se deve à maior adição de milho na dieta T0, que, na ocasião, teve o agravante da alta nos preços do milho e também do farelo de soja. O GPT (Tabela 2) por animal no T0 e no T100 foi semelhante, 15,5 e 15,2 kg respectivamente, o que indica que a grande diferença na margem bruta seja em função do baixo custo da dieta com 100\% de bagaço de laranja. O baixo teor de matéria seca da dieta T100 (Tabela 1) não prejudicou o consumo dos animais e o ganho de peso deles (Tabela 2) e, por fim, proporcionou o menor custo por kg de matéria seca e também a maior margem bruta no confinamento (Tabela 5). 


\section{Conclusões}

A substituição total do milho por bagaço de laranja reduziu em 32\% a AOL e em 35\% a espessura de gordura subcutânea. As características de desempenho animal e da carne dos cordeiros não foram alteradas pela substituição parcial ou total do milho por bagaço de laranja. A dieta com 100\% de bagaço de laranja apresentou maior viabilidade econômica.

\section{Referências}

1-Issakowicz J, Bueno MS, Issakowicz ACKS, Haguiwara MMH. Características quantitativas da carcaça e qualitativas da carne de cordeiros morada nova, santa inês e $1 / 2$ ile de france $1 / 2$ texel terminados em confinamento. B. Indústr. Anim. 2014; 71(3):217-225. Disponível em: http://revistas.bvsvet.org.br/bia/article/view/24257.

2-Rego FCA, Françozo MC, Ludovico A, De Lima LD, Lopes FG, Belan L, et al. Development, economic viability and attributes of lamb carcass from confined animals fed on different amounts of crude glycerin. Semina: Ciências Agrárias. 2015; 36(5): 3445-3454. Disponível em: http://www.uel.br/revistas/uel/index.php/semagrarias/article/view/19069/0.

3-Pinheiro RSB, Jorge AM, Mourão RC, Neto AP, Andrade EM, Gomes HFB. Qualidade da carne de cordeiros confinados recebendo diferentes relações de volumoso: concentrado na dieta. Ciênc Tecnol Alim. 2009; 29:407-411. Disponível em: http://www.scielo.br/pdf/cta/v29n2/28.pdf.

4-Susin SGI, Pires AV, Ferreira EM, et al. Digestibilidade da dieta, parâmetros ruminais e desempenho de ovinos Santa Inês alimentados com polpa cítrica peletizada e resíduo úmido de cervejaria. 2010; Rev Bras Zootec; 40(3). http://www.scielo.br/scielo.php?script=sci_arttext\&pid=S1516-35982011000300024

5-Rêgo FCA, Ludovico A, Lima LD; Belan L, Cunha Filho LFC; Zundt M. Cinética de fermentação ruminal in vitro, composição química e perfil de ácidos graxos da silagem de bagaço de laranja com fubá de milho. Sem ciências agrarias. 2013; 34(6):4037-4046. http://www.uel.br/revistas/uel/index.php/semagrarias/article/view/16506

6-NRC. National Research Council. Nutrient requirements of small ruminants. Washington: National Academy Press, 2007.

7-Mizubuti IY, Pinto AP, Ramos BMO, Pereira ES. Métodos laboratoriais de avaliação de alimentos para animais. 1 ed. Londrina, Brasil:Eduel;. 2009.

8-Sniffen CJ, O'connor JD, Van Soest PJ, Fox DG, Russell JB. A net carbohydrate and protein system for evaluating cattle diets: II. Carbohydrate and protein availability. J Anim Sci. 1992; 70:3562-3577. Disponível em: file:///C:/Users/Unopar/Downloads/jas-70-11-3562.pdf .

9--NATIONAL RESEARCH COUNCIL (NRC). Nutrient requirements of dairy cattle.7.ed.rev. Washington, D.C.: National Academy of Sciences, 381p. 2001.

10-Osório JCS, Osório MTM. Produção de carne ovina: técnicas de avaliação "in vivo" e na carcaça. Ed. Universitária PREC/UFPEL. 2005; 2:82. 
11-Sanudo C, Alfonso M, Sanchez A, Delfa R, Teixeira A. Carcass and meat quality in light lambs from different fat classes in the EU carcass classification system. Meat Science. 2000; 56(1):89-94. Disponível em: http://www.sciencedirect.com/science/article/pii/S0309174000000267?via\%3Dihub.

12-Cesar MF, Sousa WH. Carcaças ovinas e caprinas: obtenção - avaliação - classificação. 1.ed. Uberaba: Agropecuária Tropical; 2007.

13-American Meat Science Association. Meat evaluation handbook. 1st ed. Savoy: American Meat Science Association; 2001. 161p.

14-Houben JH, Van DA, Eikelenboom G, Hoving--Bolink AH. Effect of dietary vitamin E supplementation, fat level and packaging on color stability and lipid oxidation in minced beef. Meat Science.2000; 55(3): 331336. Disponível em: http://www.sciencedirect.com/science/article/pii/S0309174099001618.

15-Fernandes Júnior F, Ribeiro ELA; Mizubuti IY; Silva LDF; Barbosa MAAF; Prado OPP, Pereira ES ; Pimentel PG; Constantino C. Características de carcaça e qualidade da carne de cordeiros Santa Inês alimentados com torta de girassol em substituição ao farelo de algodão. Sem. Ciências Agrarias. 2015; 36(1):541-556. http://www.uel.br/revistas/uel/index.php/semagrarias/article/viewFile/15933/13968 .

16-Valença RL, Ferreira AD, Santos ACP, Silva BCD, Santos GRA, Lima JUN, et al. Silagem de bagaço de laranja na alimentação de cordeiros: consumo de nutrientes, desempenho e avaliação econômica. Arch. Zootec. 2017; 66 (253):81-87. Disponível em: http://www.uco.es/ucopress/az/index.php/az/article/view/2129.

17-Ávila CJC, Osório JCS, Osório MTM, Gonçalves MS, Kessler JD, Pereira JR, Ferreira OG, Crescimento e desenvolvimento dos componentes corporais de cordeiros Texel x Corriedale machos e fêmeas em diferentes sistemas de terminação. Revista electrónica de Veterinaria. 2018, 19(2):1-11 Disponível em: http://www.veterinaria.org/revistas/redvet/n020218/021801.pdf.

18-Menezes LM, Fontoura EAB; Damilano AS; Rosa RS ; Perez HA ; Gomes AFF; Cunha PT; Chagas RA ; Corrêa GF. Desempenho de cordeiros texel e corriedale mantidos em azevém em fim de ciclo. Revista electrónica de Veterinaria. 2018, 18(12):1-9 Disponível em http://www.veterinaria.org/revistas/redvet/n121217/121725.pdf.

19-Rodrigues GH, Susin I, Pires AV, Mendes CQ, Urano FS, Castillo CJC. Polpa cítrica em rações para cordeiros em confinamento: características da carcaça e qualidade da carne1. Rev. Bras. Zootec.2008; 37(10):1869-1875. Disponível em: http://www.scielo.br/scielo.php?script=sci arttext\&pid=S1516$\underline{35982008001000022 .}$.

20-Pereira MS, Ribeiro ELA, Mizubuti IY, Rocha MA, Kuraoka JT, Nakaghi EYO. Consumo de nutrientes e desempenho de cordeiros em confinamento alimentados com dietas com polpa cítrica úmida prensada em substituição à silagem de milho. Rev Bras Zootec.2008; 37(1)134-139. Disponível em: http://www.scielo.br/pdf/rbz/v37n1/v37n1a20.pdf.

21-Galvani DB, Pires CC, Wommer TP, Oliveira F, Bolzan AMS, François P. Carcass traits of feedlot crossbred lambs slaughtered at different live weights. Ciência Rural, v.38, p.1711-1717, 2008. Disponivel em: http://www.scielo.br/scielo.php?script=sci arttext\&pid=S0103-84782008000600034.

22-Astiz CS. Calidad de la canal y de la carne ovina y caprina y los gustos de los consumidores. R. Bras. Zootec., v.37, suplemento especial p.143-160, 2008. Disponivel em:

http://www.scielo.br/pdf/rbz/v37nspe/a18v37nsp.pdf.

23-Oliveira JPF, Ferreira MA, Freitas APD, Urbano SA, Silva AEM. Características de carcaça de ovinos Santa Inês alimentados com mazoferm substituindo o farelo de soja. Revista Ciência Agronômica, v. 48, n. 4, p. 708-715, 2017. Disponivel em: http://www.scielo.br/pdf/rca/v48n4/1806-6690-rca-48-04-0708.pdf. 
24-Cartaxo FQ, Sousa WH, Cesar MF, Costa RG, Cunha MGG, Neto SG. Características de carcaça determinadas por ultrassonografia em tempo real e pós-abate de cordeiros terminados em confinamento com diferentes níveis de energia na dieta. Rev Bras Zootec. 2011; 40:160-167. Disponível em: http://www.scielo.br/pdf/rbz/v40n1/v40n1a23.pdf.

25-Pereira MS, Ribeiro ELA, Mizubuti IY, Noro TTLY e Pinto AP. Carcaça e não-componentes da carcaça cordeiros recebendo polpa cítrica úmida prensada em substituição à silagem de milho. Acta Scient. animal Science. 2007; 29(1):57-62. Disponível em:

http://www.periodicos.uem.br/ojs/index.php/ActaSciAnimSci/article/view/252.

26-Almeida JCS, Figueiredo DM, Boari CA; Paixão ML; Sena JAB, Barbosa JL; Ortêncio MO; Moreira KF. Desempenho, medidas corporais, rendimentos de carcaça e cortes, e qualidade de carne em cordeiros alimentados com resíduos da agroindústria processadora de frutas. Sem: Ciências Agrárias. 2015; 36(1): 541556. Disponível em: file:///C:/Users/Unopar/Downloads/15610-90948-1-PB\%20(1).pdf.

27-Rodrigues GH, Susin I, Pires AV, Alencar SM, Mendes CQ, Gentil RS. Perfil de ácidos graxos e composição química do músculo Longissimus dorsi de cordeiros alimentados com dietas contendo polpa cítrica. Rev Bras Zootec. 2010; 39(6):1346-1352. Disponível em: http://www.scielo.br/pdf/rbz/v39n6/25.pdf 28-Silva ACF, Costa HHA, Peres MCR, Costa AC, Sousa DRS, Batista ASM, et al. Meat quality of Morada Nova lambs subjected to diferent feeding regimes. Sem ciências agrarias. 2016; 37(2):911-920. Disponível em: http://www.uel.br/revistas/uel/index.php/semagrarias/article/view/18415/1863 